\title{
LAS PINTURAS COSTERAS DE CHOMACHE Y SU CONTEXTO ECONÓMICO-SOCIAL (REGIÓN DE TARAPACÁ, NORTE DE CHILE)

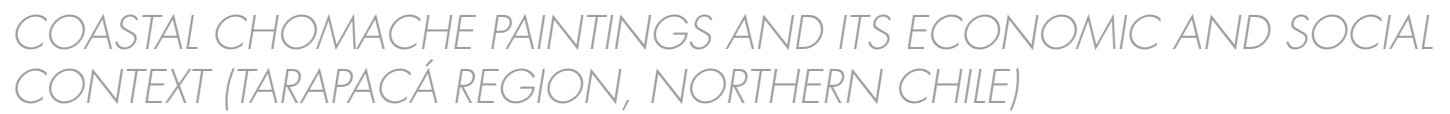

\section{Gloria Cabello*, Francisco Gallardo * * \& CAROLINA ODONE ${ }^{* *}$}

En este artículo presentamos evidencia arqueológica y etnohistórica que aporta datos sobre las íntimas relaciones establecidas entre poblaciones pescadoras y agroganaderas de la Región de Tarapacá durante el Período Intermedio Tardío (1000-1400 DC). Estas relaciones prehispánicas sirvieron de base para la organización de los sistemas colonial y republicano. La iconografía de las pinturas rupestres del sitio costero Chomache 58 y su correspondencia con materiales visuales encontrados en el arte rupestre, la alfarería, los textiles y los cestos de las localidades de los valles del interior; la presencia de productos y materias primas prehispánicas del interior en Chomache 1; las rutas caravaneras y su infraestructura asociada, más el relato de documentos históricos, nos hablan de una articulación regional que evidencia no solo una complementariedad ecológica, sino también social y cultural.

Palabras clave: iconografía, economía, interacción social

In this article we present archaeological and ethno-bistorical evidence that provides data on the close ties that existed between fishing and farming-herding populations of Tarapacá Region in the Late Intermediate Period (1000-1400 AD). These preHispanic relations laid the foundation for the organization of the colonial and republican systems. Different kinds of evidence - the iconography of the paintings found at the Chomache 58 coastal site and its correspondence with visual materials found in rock art, pottery, textiles and baskets from villages of the inland valleys; the presence of inland pre-Hispanic products and raw materials at Chomache 1; caravan routes and their associated infrastructure; and historical documents-tell of a regional network characterized not only by ecological but also social and cultural complementarity.

Key words: iconography, economy, social interaction
En la década de los cincuenta del siglo pasado, Herbert Hornkohl (1954) dio a conocer un extraordinario panel de grabados rupestres en la costa de Antofagasta, cuyas formas (camélidos y peces) le parecieron un testimonio de los vínculos entre el litoral y los valles del interior. Durante años su descubrimiento permaneció como un dato curioso de importancia menor respecto de otras materialidades culturales. Pero el aumento en los registros en la actualidad sugiere que este modo de expresión fue parte significativa de la vida social y cultural costera (Núñez \& Contreras 2006; Gallardo 2009b; Ballester \& Gallardo 2011).

Recientemente hemos relevado un nuevo sitio con pinturas al norte de la desembocadura del río Loa, en las cercanías de caleta Guanillos, conocida por sus depósitos de sal, cobre, plata y guano (Billinghurst 1886; Riso Patrón 1924). Se trata de un gran bloque granítico con pinturas rojas y blancas, localizado en una punta rocosa que cierra por el sur la estrecha caleta de Chomache. $\mathrm{Su}$ arte rupestre se caracteriza por figuras geométricas regulares e irregulares, camélidos de cuerpo rectangular, albacora y otros peces. Esta iconografía tiene importantes correspondencias con materiales visuales encontrados en el arte rupestre y la alfarería de las localidades arqueológicas de los valles del interior durante el Período Intermedio Tardío (1000-1400 DC).

* Gloria Cabello, Centro de Investigaciones del Hombre en el Desierto, Universidad de Tarapacá, Arica, Chile, email: glcabello@gmail.com

* Francisco Gallardo, Museo Chileno de Arte Precolombino, Bandera 361, Santiago, Chile, email: fgallardo.ibanez@gmail.com

*** Carolina Odone, Pontificia Universidad Católica de Chile, Santiago, Chile, email: modoneco@uc.cl 
En el presente artículo nos proponemos considerar contextualmente este sitio de arte rupestre, apelando a la información arqueológica y etnohistórica regional. No pretendemos dar cuenta de la variedad de formas o los significados del panel de pinturas, sino apuntar a su valor social relativo dentro de un marco de relaciones entre distintas poblaciones alojadas en las costas y los oasis del interior. En este sentido, debe tenerse en cuenta que en tanto los estudios del sur de la Región de Tarapacá son por ahora limitados, nuestro trabajo permanece en el nivel de la formulación de un modelo histórico social. Es decir, un conjunto de hipótesis de trabajo que descansan tanto en los registros históricos tempranos y recientes, como en aquellos de orden arqueológico. Nuestro examen de estos permite afirmar que las poblaciones pescadoras y agroganaderas de la Región de Tarapacá operaban bajo relaciones de interacción social, cuya estructura sirvió de base para la organización de los sistemas colonial y republicano. Crearon vínculos estrechos y recurrentes que alentaron la producción de un imaginario visual común, solidario a las estrategias de complementariedad ecológica y social vigentes durante los períodos prehispánico y colonial en el norte de Chile (p. e., Núñez 1962; Murra 1972; Martínez 1985; Núñez \& Dillehay 1995 [1979]; Hidalgo 2004).

\section{LAS PINTURAS RUPESTRES DE CHOMACHE, SU ICONOGRAFIAA Y DISTRIBUCIÓN EN EL NORTE DE CHILE}

Chomache 58 corresponde a un sitio exclusivo de pinturas rupestres ubicado $1,7 \mathrm{~km}$ al sur de la actual caleta San Marcos y unos $40 \mathrm{~km}$ al norte de la desembocadura del río Loa (fig. 1). ${ }^{1}$ Su emplazamiento geográfico corresponde a una puntilla que se proyecta cerca de $1 \mathrm{~km}$ desde la cordillera de la Costa hacia el océano Pacífico. En ella abundan los afloramientos graníticos de gran altura, algunos de los cuales caen al mar, mientras otros emergen sobre pequeñas playas de arena blanca. En uno de estos se pintó la superficie que se opone al $\operatorname{mar}\left(20^{\circ} \mathrm{W}\right)$, de modo que si se mira al poniente, se ven tanto las pinturas como el océano (fig. 2).

El panel es levemente rugoso, plano y casi recto, con dimensiones de 3,2 $\mathrm{m}$ de largo; 3,3 $\mathrm{m}$ de ancho y 3,7 m de alto. Los motivos ocupan casi toda su

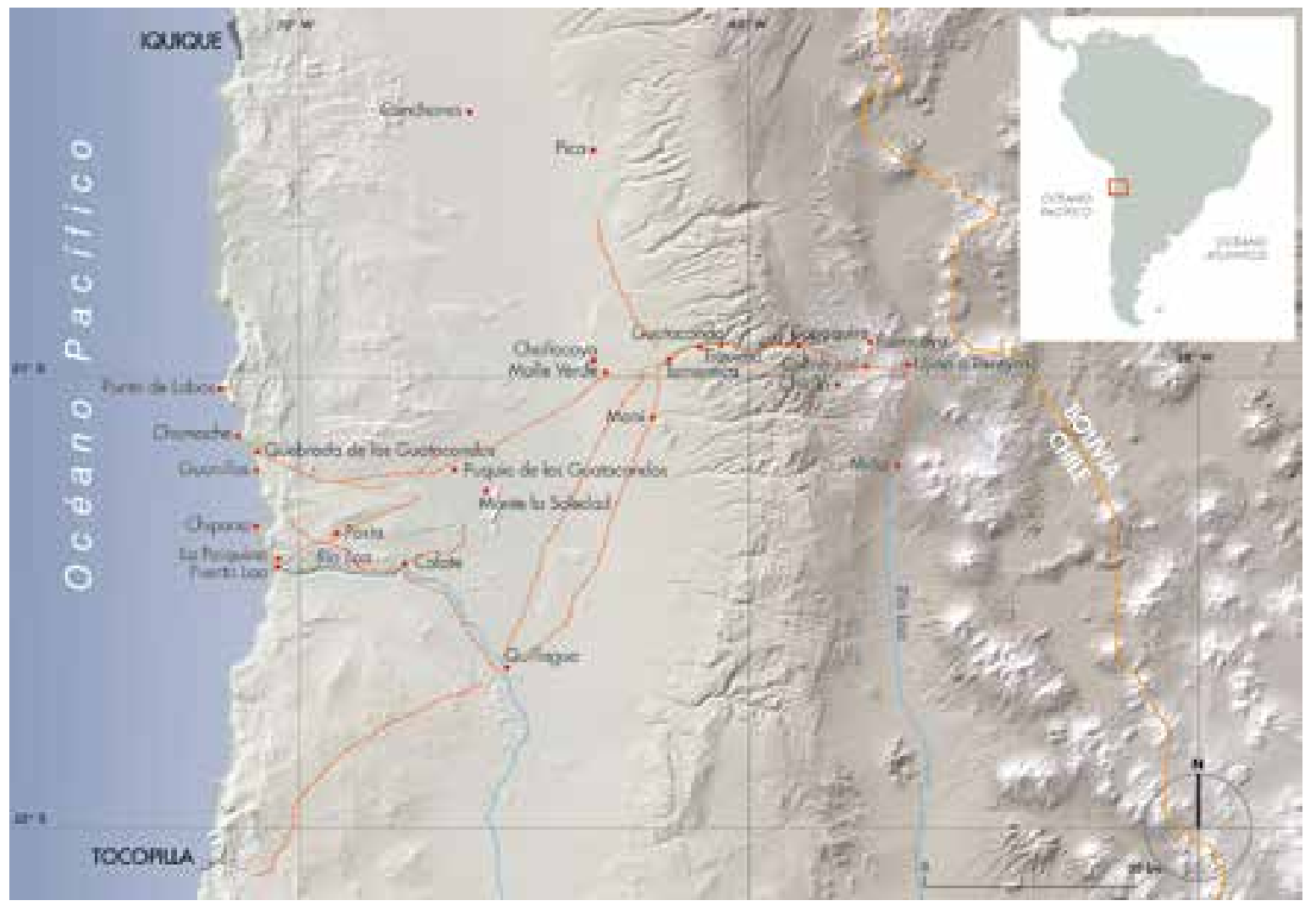

Figura 1. Ubicación geográfica de los sitios y las rutas que se mencionan en el texto.

Figure 1. Geographic location of the sites and routes mentioned in the text. 


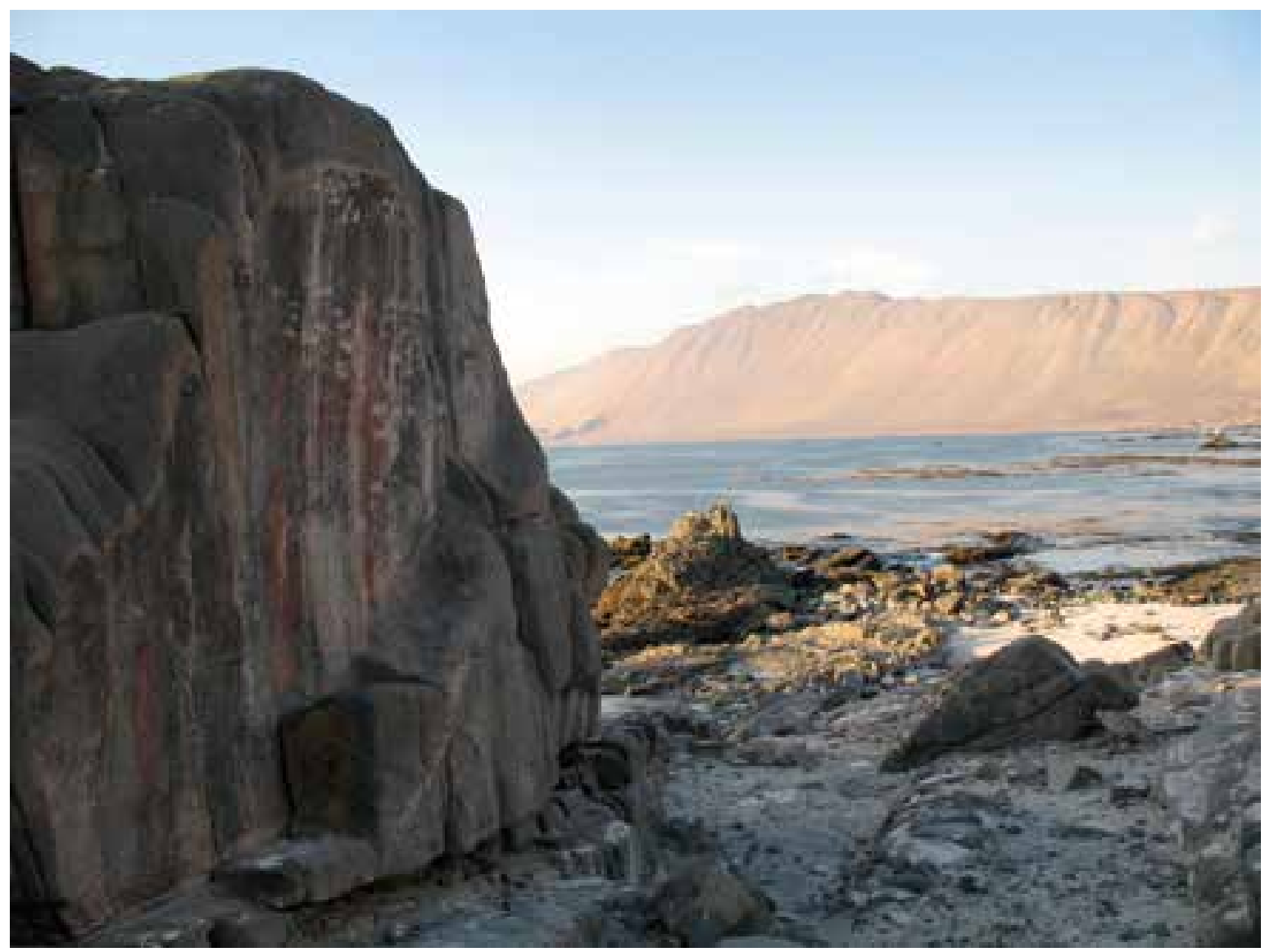

Figura 2. Emplazamiento del panel pintado de Chomache 58. Figure 2. The painted panel at Chomache 58.

extensión $(70 \%)$, circunscribiéndose hacia el centro (entre 2,83 $\mathrm{m}$ y $0,80 \mathrm{~m}$ de altura), pero segregados en tres sectores (fig. 3).

Debido al regular estado de conservación de las pinturas -afectadas por condiciones salinas y excrementos de aves- y la superposición de algunas de las representaciones que conforman el panel, se relevaron solo aquellas figuras bien definidas, identificando un total de 90 motivos. Se trata de pinturas monocromas, más de dos tercios blancas, seguidas lejanamente por las rojas y naranjas, detectándose un solo caso policromo, donde intervienen rojo, blanco y morado.

En cuanto a los detalles técnicos, el trazo de ejecución es siempre continuo para figuras que en un 98\% de los casos fueron realizadas mediante una gráfica areal, en la que el diseño coincide con la superficie pintada.

En términos iconográficos, un $74 \%$ corresponde a referentes desconocidos, cuyas formas relacionamos equitativamente con figuras geométricas simples o compuestas $(n=33 \mathrm{c} / \mathrm{u}){ }^{2}$ El 26\% restante corresponde a zoomorfos $(n=23)$ y antropomorfos $(n=1)$ (Tabla 1$)$.
La importancia de este panel pintado radica en su repertorio iconográfico, pues este aparece en distintos soportes visuales de los valles y las planicies del interior. Entre los geométricos simples destacan el triángulo escalerado que observamos en la alfarería San Miguel-B, propia de los Valles Occidentales, pero que aparece también en distintos sitios de la costa y el interior de Tarapacá durante el Período Intermedio Tardío (PIT en adelante) (Uribe 1999, 2004) (Tabla 2: A). Icono que además está presente en pinturas rupestres, geoglifos, cestería, textiles y calabazas pirograbadas de Tarapacá y el Loa Medio (Montell 1926; Ryden 1944; Oyarzún 1979; Meighan 1980; Zlatar 1984, por citar algunos) (fig. 4a).

Entre los geométricos compuestos, los rectángulos con apéndices superiores verticales se encuentran grabados en bloques de Tarapacá-47 y los triángulos escalerados triples sobre una recta en textiles tarapaqueños con iconografía de Valles Occidentales (Núñez \& Briones 1968; Agüero 2007) (Tabla 2: B y C, respectivamente). ${ }^{3}$ Mientras que el triángulo con apéndice en coma está 

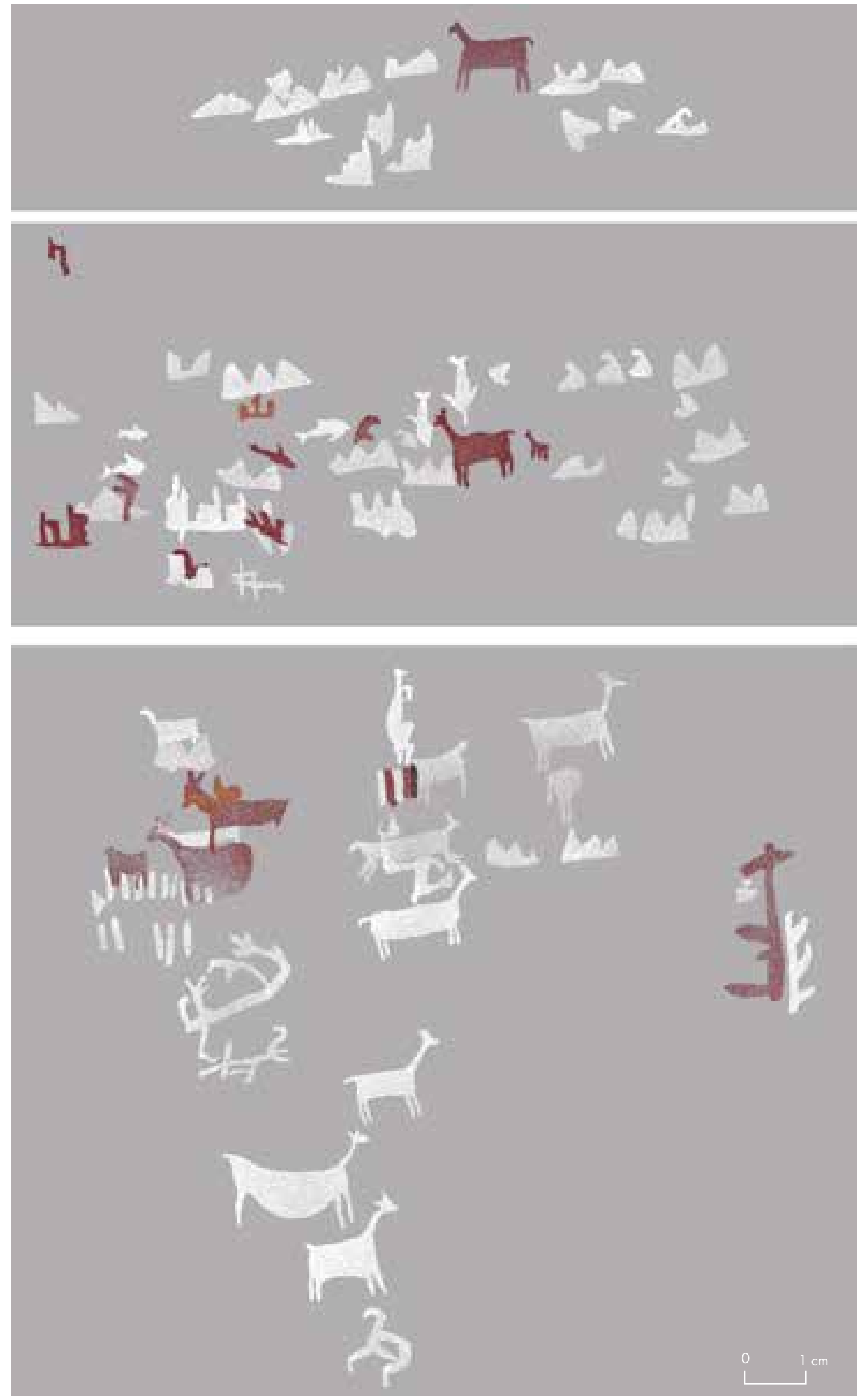

Figura 3. Vista general de los motivos por sector del panel (dibujo Paulina Chávez).

Figure 3. General diagrams of the motifs on different panel segments (diagram by Paulina Chávez). 
Tabla 1. Síntesis iconográfica de Chomache 58.

Table 1. Summary of Chomache 58 iconography.

\begin{tabular}{|c|c|c|c|c|c|c|c|}
\hline Referente & Grupo & Tipo & $\begin{array}{l}\mathrm{N}^{\circ} \\
\text { total }\end{array}$ & $\begin{array}{c}\mathrm{N}^{\circ} \\
\text { blanco }\end{array}$ & $\begin{array}{c}\mathrm{N}^{\circ} \\
\text { rojo }\end{array}$ & $\begin{array}{c}\mathrm{N}^{\circ} \\
\text { naranjo }\end{array}$ & $\begin{array}{c}\mathrm{N}^{\circ} \text { blanco, rojo } \\
\text { y morado }\end{array}$ \\
\hline \multirow{3}{*}{ Conocido } & Antropomorfos & & 1 & 1 & & & \\
\hline & \multirow{2}{*}{ Zoomorfos } & Camélido & 17 & 10 & 7 & & \\
\hline & & Pez & 6 & 5 & 1 & & \\
\hline \multirow{15}{*}{ Desconocido } & \multirow{8}{*}{$\begin{array}{l}\text { Geométricos } \\
\text { simples }\end{array}$} & Triangular & 2 & 2 & & & \\
\hline & & $\begin{array}{c}\text { Triangular de lado } \\
\text { en B }\end{array}$ & 4 & 4 & & & \\
\hline & & $\begin{array}{l}\text { Triangular } \\
\text { escalerado }\end{array}$ & 3 & 3 & & & \\
\hline & & Triangular invertido & 1 & 1 & & & \\
\hline & & Trapezoidal & 3 & 3 & & & \\
\hline & & Línea & 6 & 5 & 1 & & \\
\hline & & Greca & 3 & & 3 & & \\
\hline & & Irregular & 11 & 7 & 4 & & \\
\hline & \multirow{7}{*}{$\begin{array}{l}\text { Geométricos } \\
\text { compuestos }\end{array}$} & $\begin{array}{l}\text { Triangular con } \\
\text { apéndice en coma }\end{array}$ & 4 & 4 & & & \\
\hline & & Triangular doble & 17 & 15 & 2 & & \\
\hline & & Triangular triple & 5 & 3 & & 2 & \\
\hline & & $\begin{array}{c}\text { Rectángulo con } \\
\text { apéndices superiores } \\
\text { verticales }\end{array}$ & 1 & 1 & & & \\
\hline & & $\begin{array}{c}\text { Triangular } \\
\text { escalerado triple } \\
\text { sobre recta }\end{array}$ & 1 & 1 & & & \\
\hline & & Líneas sucesivas & 3 & 2 & & & 1 \\
\hline & & $\begin{array}{l}\text { Línea vertical con } \\
\text { apéndices oblicuos }\end{array}$ & 2 & 1 & 1 & & \\
\hline
\end{tabular}

en la alfarería PIT de Valles Occidentales de los tipos San Miguel-B y Pocoma Gentilar, así como en calabazas pirograbadas de sitios de la región de Tarapacá y el Loa Medio (Ryden 1944; Uribe 1999, 2004) (Tabla 2: D y fig. 4b).

Los triángulos en traslación horizontal se hallan en la alfarería de Valles Occidentales desde el Período Medio, con los tipos cerámicos Cabuza, Maytas Chiribaya y San Miguel-A, y en la del PIT, con tipos locales San Miguel-B y Pocoma Gentilar y en el tipo altiplánico Taltape (Dauelsberg 1984; Zlatar 1984; Uribe 1999, 2004) (Tabla 2: E). ${ }^{4}$ También están ampliamente presentes en geoglifos, grabados rupestres y textiles de Tarapacá, así como en calabazas del Loa Medio (Ryden 1944; Mostny 1970a y b; Oyarzún 1979; Zlatar 1984; Cerda et al. 1985; Vilches \& Cabello 2011) (fig. 4c).
Entre los zoomorfos de Chomache 58 reconocemos camélidos siempre de cuerpo cuadrangular a rectangular ( $s i$ bien el vientre varía de recto a curvo, hacia arriba o hacia abajo), con cuatro patas rígidas que no expresan movimiento y cola curva hacia abajo. ${ }^{5}$ En lo principal, las orejas se representan en pares, pero también solo una, ratificando la posición invariablemente de perfil (Tabla 2: F). Esta forma es la más usada para representar estos animales en geoglifos y grabados rupestres tarapaqueños (Núñez \& Briones 1968; Niemeyer \& Schiappacasse 1981; Cerda et al. 1985; Núñez 1985; Espinosa 1998; Briones et al. 2005; Vilches \& Cabello 2011) (fig. 5a); iconografía que está presente en textiles y cestería de la misma zona y del Loa Inferior (Zlatar 1984; Núñez 2002).

Por último, en Chomache 58 registramos peces de perfil con detalles anatómicos de aletas y cola, muy 
A

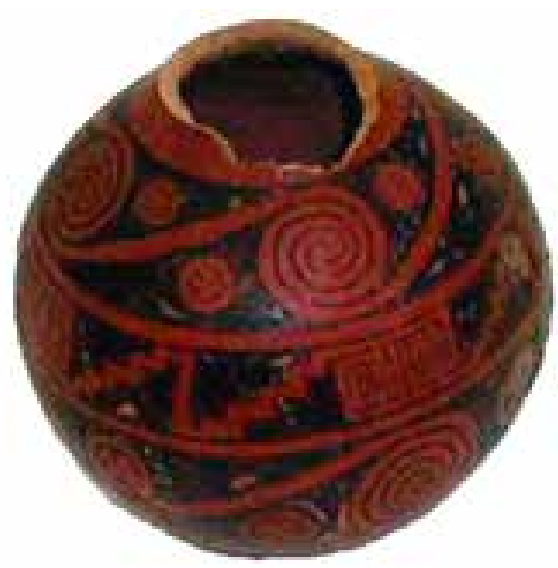

B

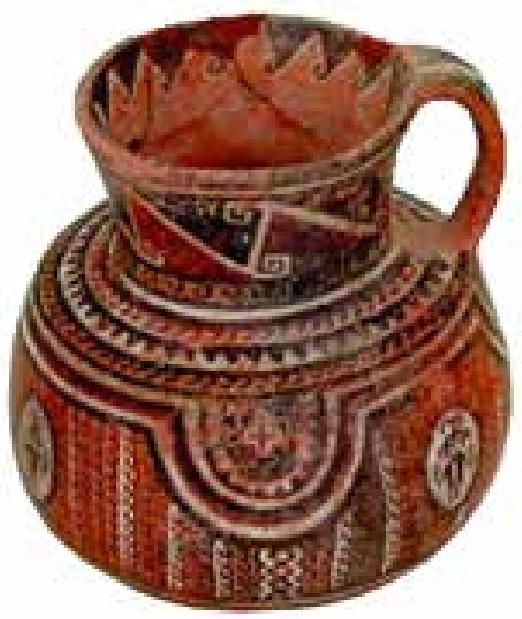

C

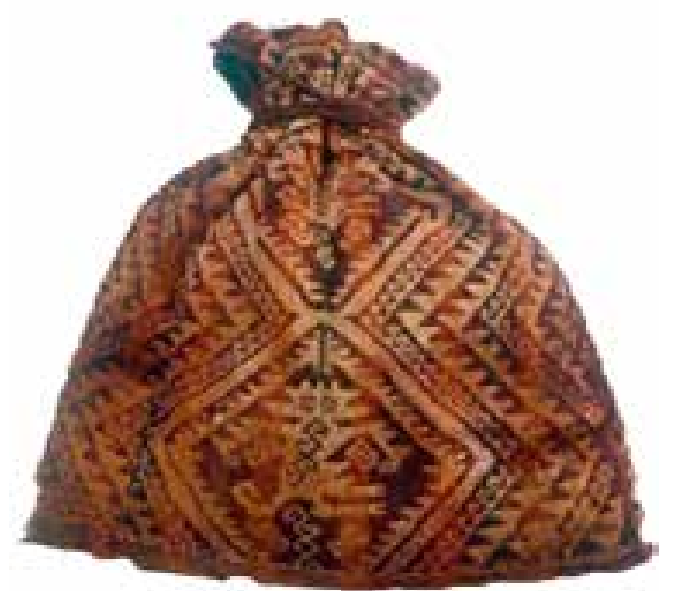

Figura 4. a) Triángulo escalerado en calabaza pirograbada; b) Triángulos con apéndice en coma en jarra Pocoma Gentilar; c) Triángulos en traslación horizontal en bolsa (colección Santa Cruz Yaconi).

Figure 4. a) Stepped triangle motif on pyro-engraved gourd; b) Triangles with flourish on Pocoma Gentilar pitcher; c) Triangles in horizontal translation on a woven bag (Santa Cruz Yaconi collection). similares a los observados en geoglifos tarapaqueños y en pinturas del Loa Inferior (Briones \& Chacama 1987; Núñez 2002) (Tabla 2: G y fig. 5b).

Junto a los motivos simples, también se aprecian aquí conjuntos organizados cuya disposición al interior del panel responde a una composición (sensu Gallardo 2009a). Se trata mayoritariamente de motivos del mismo tipo que se replican según el movimiento simétrico de traslación $(\mathrm{n}=14)$. A diferencia de los motivos geométricos compuestos en que la traslación se daba por lo general sobre el eje horizontal, aquí ocurren en forma equitativa también sobre el eje oblicuo $(n=5 \mathrm{c} / \mathrm{u}), \mathrm{y}$ excepcionalmente vertical $(n=3)$ y doble, vertical y horizontal (n=1) (fig. 3).

Esta clase de composición simétrica se da en todos los referentes: cinco casos de geométricos compuestos, cinco de geométricos simples y dos de zoomorfos. Existen también tres casos en que se combinan geométricos compuestos con zoomorfo, antropomorfo y geométrico simple. Si bien la composición es siempre monocroma, resulta interesante que se trata mayoritariamente de pinturas blancas, presentándose solo un caso en rojo, que involucra un camélido adulto y una cría en composición escénica, en que los motivos se relacionan por actividad (Gallardo 2009a).

\section{LA ARQUEOLOGÍA DE CHOMACHE Y SUS VINCULOS CON LOS VALLES DEL INTERIOR}

Chomache 58 forma parte de un conjunto de evidencias prehispánicas entre las que destacan los sitios de funebria Chomache 51, 61 y 62 y el habitacional Chomache 1, con cinco recintos rectangulares aglutinados. Este último es particularmente interesante, no solo por su proximidad al panel pintado ( $160 \mathrm{~m}$ al SSW), sino porque representa un asentamiento de pescadores de tipo familiar similar a los observados en Pisagua, Camarones y la desembocadura del Loa: recintos de forma rectangular, aterrazados, colindantes y vinculados a aguadas (Spanhi 1967; Núñez 1971; Llagostera 1989; Adán \& Urbina 2004; Urbina et al. 2009) (fig. 6).

La excavación estratigráfica del $50 \%$ del Recinto 1 señala al menos tres ocupaciones prehispánicas sucesivas, donde las más intensas fueron fechadas hacia fines del Período Formativo (650-770 DC) e inicios del Intermedio Tardío (1220-1290 DC). ${ }^{6}$ En ellas se encontraron fragmentos de pequeños tiestos para transportar y servir alimentos pertenecientes a tipos cerámicos formativos vinculados con Caserones, Quillagua y el Loa Medio, y cerámica para preparar y servir alimentos de los 
Tabla 2. Relación iconográfica entre Chomache 58 y el norte de Chile. Table 2. Iconographic connections between Chomache 58 and northern Chile.

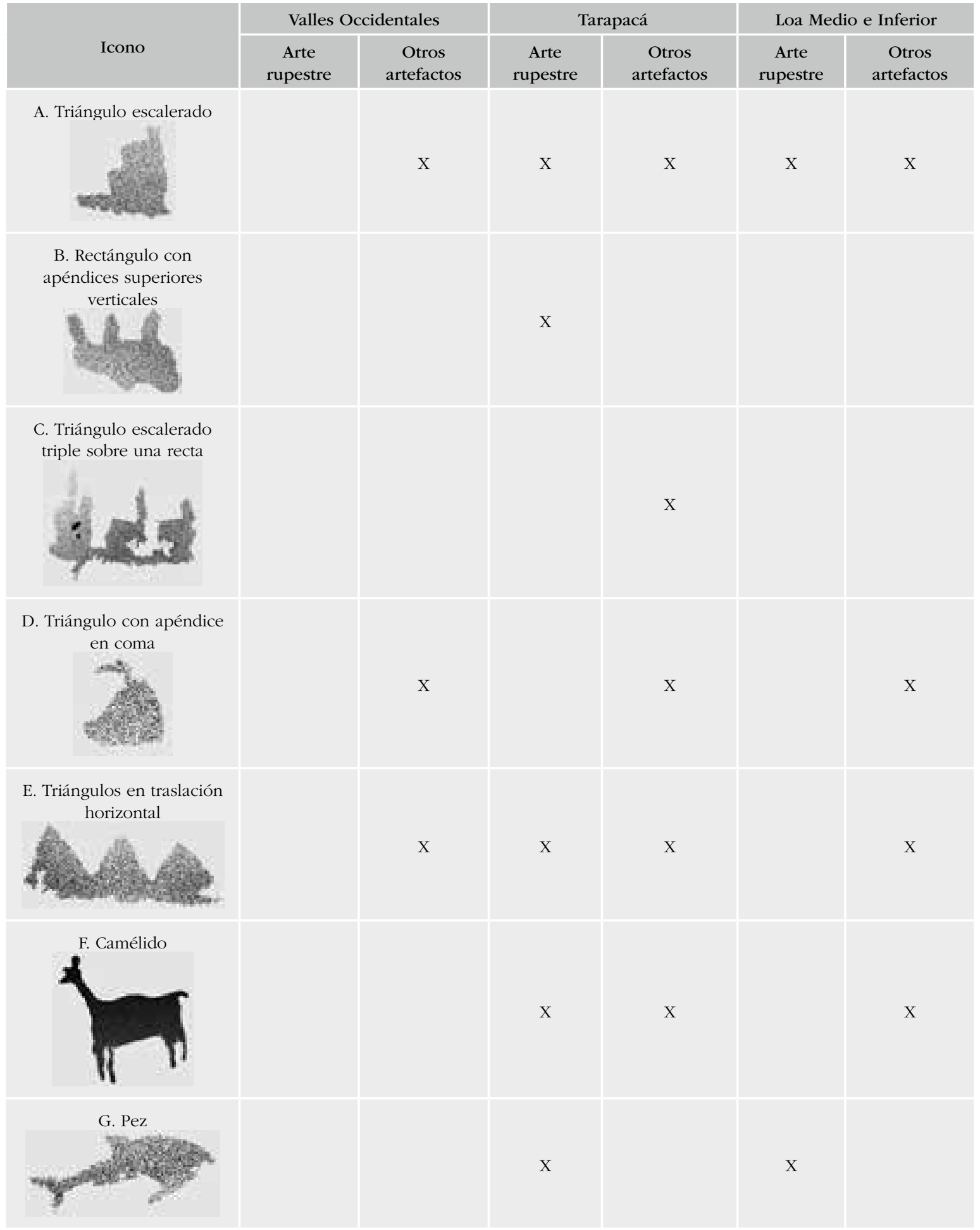


A

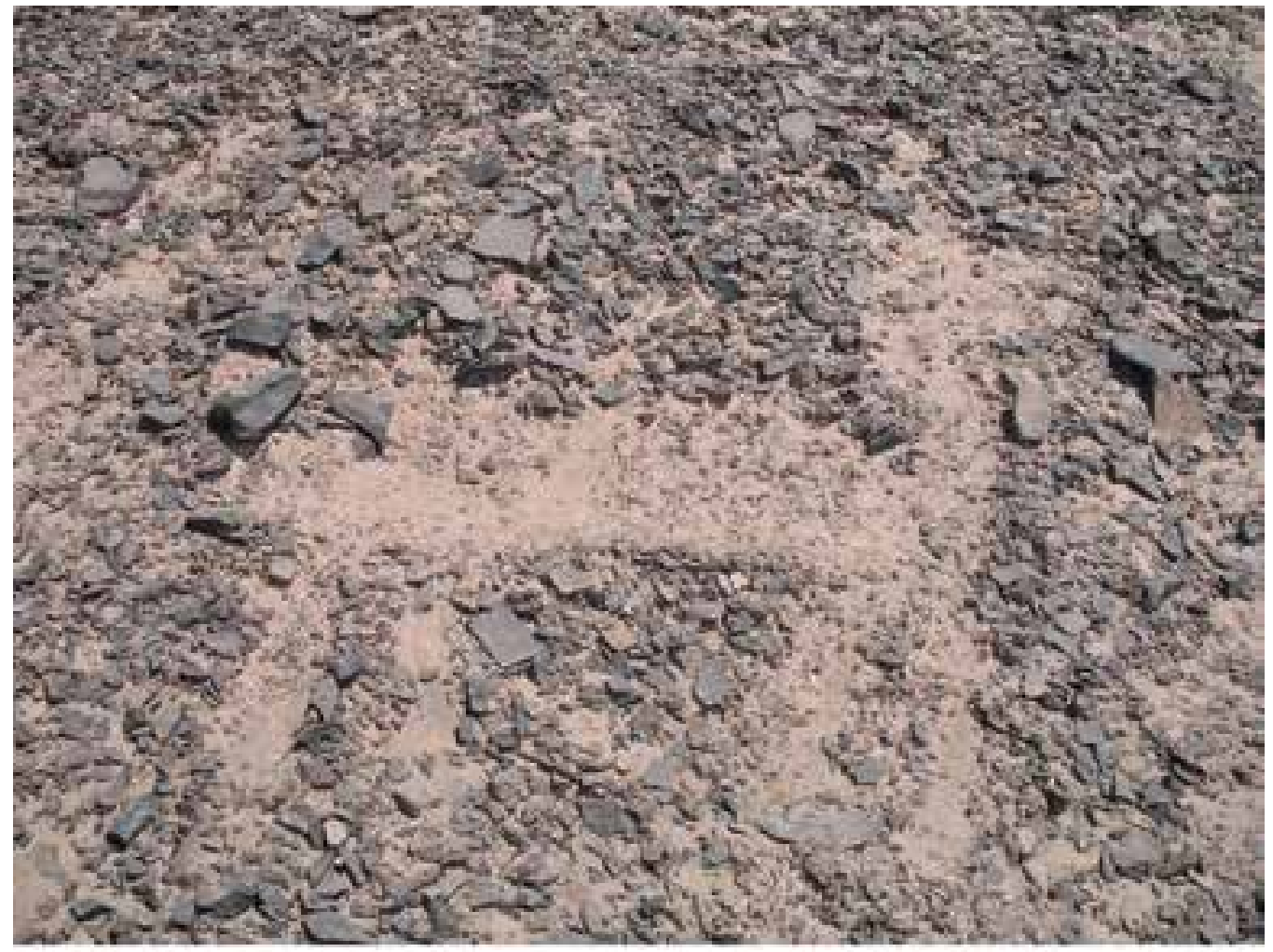

B

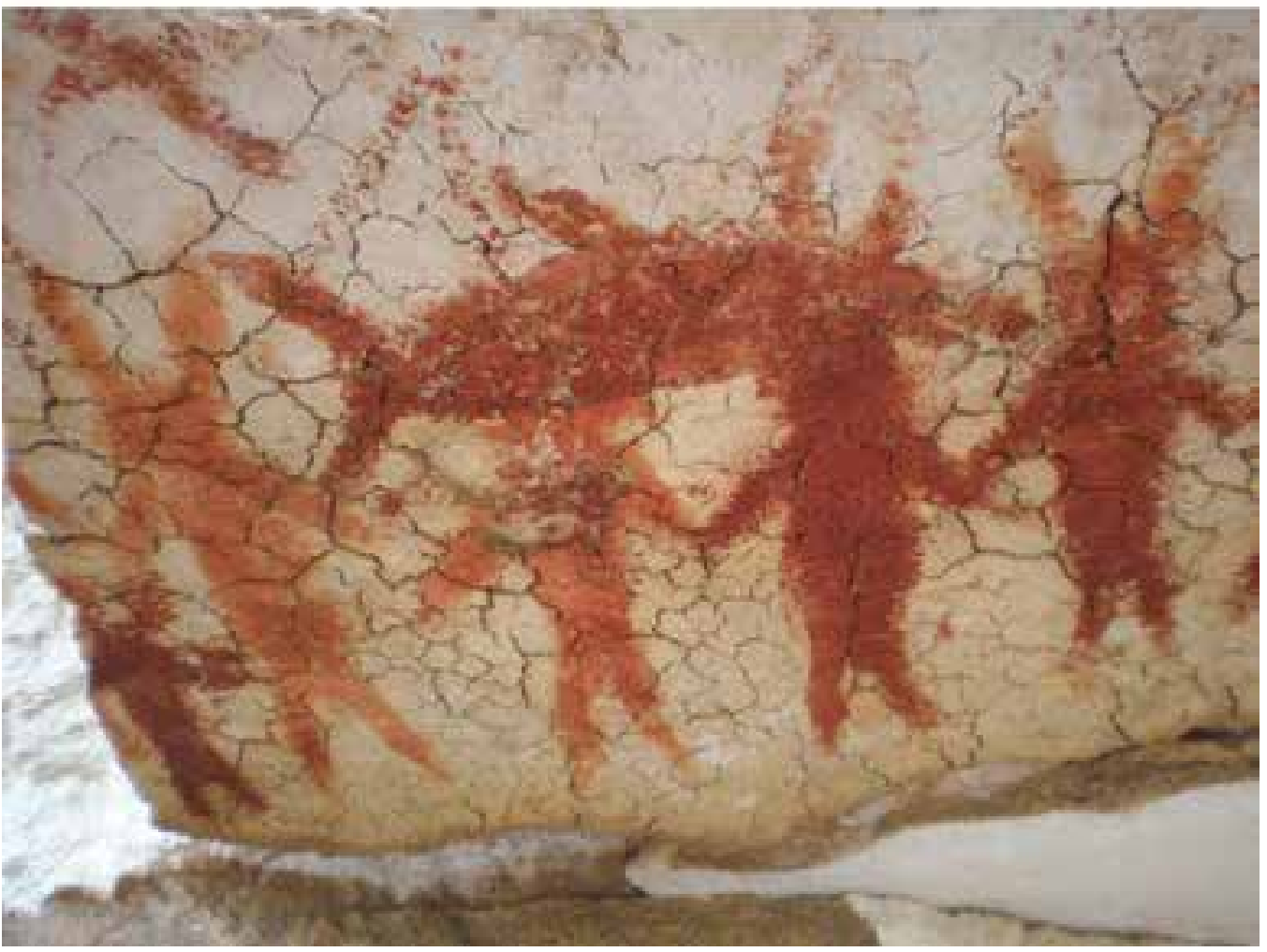

Figura 5. a) Camélido cuadrangular en geoglifo de la ruta Tamentica-Quillagua; b) Pez pintado de quebrada Amarga.

Figure 5. a) Quadrangular camelid geoglyph on the Tamentica-Quillagua route; b) Painted fish in the Amarga Ravine. 


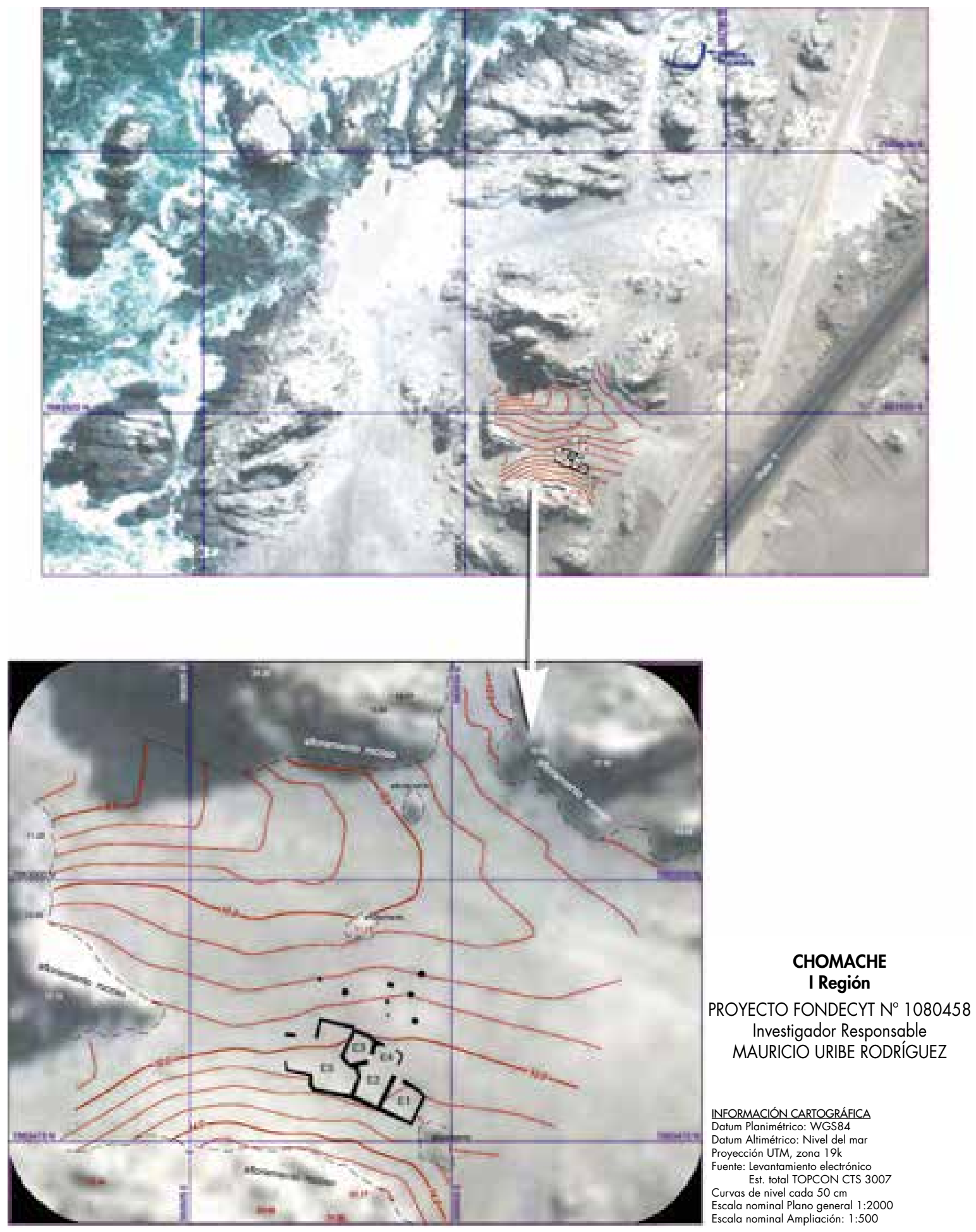

Figura 6. Sitios Chomache 58 y Chomache 1 (fuente: Urbina et al. 2009).

Figure 6. Chomache 58 and Chomache 1 sites (source: Urbina et al. 2009). 
Tabla 3. Presencia de productos en Chomache 1 en relación con su origen. Table 3. Origin of products found at Chomache 1.

\begin{tabular}{|c|c|c|}
\hline Producto & Origen local & Origen foráneo \\
\hline Cerámica & & $\begin{array}{c}\text { Pica Charcollo (PCh) } \\
\text { Ayquina (AIQ) } \\
\text { Arica No Decorado (AND) } \\
\text { Posible Turi Gris Alisado (TGA?) }\end{array}$ \\
\hline Vegetal & $\begin{array}{c}\text { Huiro (Macrocystis sp.) } \\
\text { Cochayuyo (Lessonia sp.) } \\
\text { Junquillos (Scirpus sp.) } \\
\text { Sorona (Tessaria absinthioides) } \\
\text { Bulbos comestibles (Zephyra elegans) } \\
\text { Copao (Eulychnia iquiquensis) }\end{array}$ & $\begin{array}{c}\text { Algarrobo (Prosopis sp.) } \\
\text { Molle (Schinus molle) } \\
\text { Madera } \\
\text { Zapallo (Cucurbita sp.) } \\
\text { Calabaza (Lagenaria sp.) } \\
\text { Algodón (Gossypium sp.) } \\
\text { Quinua (Chenopodium quinoa) }\end{array}$ \\
\hline Fauna & & $\begin{array}{l}\text { Camélido indeterminado } \\
\text { Vicuña (Vicugna vicugna) }\end{array}$ \\
\hline $\begin{array}{c}\text { Peces } \\
\text { (más representados) }\end{array}$ & $\begin{array}{l}\text { Bilagay (Cheilodactylus variegatus) } \\
\text { Jurel (Trachurus symmetricus) } \\
\text { Corvina (Cilus gilberti y Corvina sp.) } \\
\text { Pejeperro (Semicossyphus maculatus) } \\
\text { Cojinova (Seriolella violacea) } \\
\text { Merluza común (Merluccius gayi) } \\
\text { Rollizo (Pinguipes chilensis) }\end{array}$ & \\
\hline $\begin{array}{c}\text { Moluscos } \\
\text { (más representados) }\end{array}$ & $\begin{array}{c}\text { Caracol negro (Tegula atra) } \\
\text { Loco (Concholepas concholepas) } \\
\text { Lapa (Fissurella sp.) } \\
\text { Almeja (Protothaca taca) } \\
\text { Choro zapato (Choromytilus chorus) } \\
\text { Chitón (Chitón spp.) } \\
\text { Caracol no comestible (Oliva peruviana) }\end{array}$ & \\
\hline Otros & & Metal, lítico \\
\hline
\end{tabular}

componentes PIT Pica-Tarapacá y Loa-San Pedro, más algunas evidencias no decoradas de Valles Occidentales (Uribe 2009).

Junto a ellas existen abundantes productos locales, de explotación marítima y terrestre, más algunos de origen foráneo (Tabla 3). ${ }^{7}$ Los primeros, parecen estar enfocados tanto al consumo como a la producción marítima, como lo atestigua una alta variedad de peces y moluscos, cuyo importante volumen alimentario y fácil obtención representan un manejo óptimo del recurso (González 2009; Valenzuela 2009). Su producción excedentaria podría estar evidenciada también en el Recinto 3, que presenta solo un estrato definido como basural secundario con una enorme cantidad de conchas enteras sobre el piso preparado del recinto (Méndez-Quirós 2009).

No menos importante resultan otros usos de los productos locales: conchas como contenedores de pigmentos (loco y caracol negro) u ornamentación (Oliva peruviana) (Valenzuela 2009); algas marinas anudadas y en ovillo para cordelería, y espinas de cactus para agujas, además de sus semillas que son indicio del consumo de su fruto (Vidal \& García 2009).

Los productos foráneos, en cambio, estarían principalmente destinados a la elaboración de instrumentos, además del consumo. De esta forma, en Chomache 1 se registraron no solo los frutos comestibles de algarrobos y molles, sino también maderas que se tallaron in situ para servir posiblemente de astiles, como lo atestigua la presencia de virutas (Vidal \& García 2009). Lo mismo ocurre con los restos de metal de cobre (gotas y recortes) y líticos (desechos de talla bifacial silíceos), donde las primeras etapas de reducción y/o procesamiento se realizarían en el lugar de aprovisionamiento de las materias primas, pero los instrumentos serían labrados en el sitio (García 2009; Riveros 2009; Vidal \& García 2009). 
El registro de huesos de camélidos (entre los que destaca un astrágalo de vicuña), frutos y semillas vegetales (zapallo, calabaza y quinua) atestiguan el consumo en el sitio de productos del interior. Pero son evidentes también otros usos para los vegetales, como fragmentos de calabaza retomados para servir de tapa o continente (este pirograbado). Por último, la presencia de semillas, fibras e hilos de algodón señalan que estos pudieron transportarse desde los valles interiores al campamento, donde se llevó a cabo su limpieza y posterior hilado, para servir probablemente a la confección de sedales (Vidal \& García 2009).

$\mathrm{Al}$ igual que la iconografía del panel, este sitio señala una estrecha relación entre la costa y el interior, en que los productos denominados foráneos se encuentran integrados a la vida cotidiana de los pescadores que lo habitaron, al menos durante momentos finales del Período Formativo e inicios del Intermedio Tardío. Dicha ocupación se daría de forma continua y permanente, como lo avala la presencia de cementerios cercanos.

\section{CHOMACHE Y SU ARTICULACIÓN EN LA ECONOMIIA REGIONAL}

Chomache 58 se emplaza en el extremo de una ruta caravanera que conecta la costa con Guatacondo, Pica y Quillagua. El punto de origen costero de esta huella que se interna en dirección a Guatacondo y otras localidades se encuentra a pocos kilómetros al norte en la caleta de Guanillos, sendero donde se han registrado geoglifos que indican su uso en épocas del Período Intermedio Tardío (Núñez 1976; Cerda et al. 1985). Un reconocimiento de esta vía de circulación a la altura del salar de Llamara nos permitió identificar una antigua posada para los viajeros y otros sitios de vivienda históricos, con claras evidencias de reutilización de instalaciones prehispánicas. Por lo visto, esta articulación permitió un flujo de personas, bienes e información que se mantuvo en operaciones hasta el período republicano temprano. Como la arqueología de este sector es aún pobre, utilizaremos los registros coloniales y republicanos como un modo preliminar de acceso a las fórmulas económicas y sociales que permitían satisfacer los imperativos de la complementariedad ecológica y social tejida por las comunidades de la región.

\section{Período histórico (siglos XVI-XIX)}

Para el período colonial, la información sobre el área de Chomache-Guanillos y sus inmediaciones es fragmentaria. Sin embargo, se puede concluir que hacia el año 1565
Chomache y sus alrededores fueron incorporados al tenientazgo de Tarapacá, unidad político-administrativa que se extendía entre la quebrada de Camarones por el norte y Tocopilla por el sur. El tenientazgo fue dividido en dos sectores, uno desde el mar a la cordillera, entre las quebradas de Camarones y Mamiña. Y otro, entre los valles de Pica y Guatacondo, incluyendo paisajes de costa, precordillera y altiplanicie, cuyo límite meridional estaba demarcado por las localidades de Quillagua, Puerto Loa y caleta Duendes, situadas en las cercanías de Tocopilla, o bahía Algodonales (Billinghurst 1893; Odone 2011).

El valle de Pica, particularmente el pueblo de San Andrés, era la cabecera del control administrativo hispano del sector meridional de Tarapacá, incluyendo los pueblos de San Salvador de Guatacondo y Nuestra Señora de la Purificación o Puerto Loa. Desde esos asentamientos se articuló la incorporación de los grupos indígenas a las actividades económicas hispanas focalizadas inicialmente en la costa del río Loa, los valles de Quillagua, Guatacondo, Pica y la cordillera inmediata.

A partir de la Visita General al Perú del virrey Toledo (1570-1575), se efectuó la reducción de la población en los pueblos de San Andrés y de Loa. Los indígenas de la encomienda y repartimiento de Pica y Loa estaban obligados a pagar su tributo en piezas de ropa de algodón, "aves de castilla" y pescado salado y seco. Este recurso, debido a su gran eficiencia productiva y alta demanda, se constituyó tempranamente en uno de los productos clave que circularon tanto dentro como fuera del espacio tarapaqueño para abastecer, entre otros, los requerimientos del mercado potosino. ${ }^{8}$ De los enclaves productivos costeros, Puerto Loa fue una de las localidades importantes en la organización hispana local. Aquí la población indígena encomendada efectuaba las actividades de explotación de los recursos marítimos: "quince yndios camanchacas del puerto de Loa que pagan su tributo en pescado y aunque están en dicho puerto otros cinco que se sacaron del pueblo de Piza del ayllo Arasaya para chasques" (AGI, Charcas 21, f. 1r, citado por Odone 1994: 90). Mientras que para la pesca y sus actividades asociadas se utilizaba mano de obra indígena de la costa, para la circulación del pescado, seco y salado, eran los indígenas del interior los encargados de su transporte, en este caso particular, indígenas procedentes del valle de Pica.

Los españoles, a través de una autoridad establecida en el litoral, el portero del Loa, eran quienes controlaban la extracción de pescado y su posterior circulación hasta el mercado de Potosí. En este circuito, el valle de Quillagua ocupaba un lugar central, pues a partir del siglo XVII ya contaba con pastos apropiados, básicamente 
alfalfa, para la mantención de ganado mular, el que era utilizado para el transporte de pescado (Villalobos 1979). Este valle no solo fue orientado a la producción de forraje para sustento de ganado mular, sino también para "vacas y ganado de cerda" (Paz Soldán 1878: 54 y 55).

A su vez y durante el período colonial, Quillagua es significado documentalmente como un espacio donde a inicios del siglo xVIII aún existían "muchos algarrobales y una acequia muy dilatada de los gentiles y según los vestigios habían solido sembrar maices y quinuas". El valle era un territorio socialmente compartido: "[cortado] ajo son las tierras de los indios de Pica, y de ahí para arriba son las tierras de Atacama" (Paz Soldán 1878: 57). Contaba con un importante bosque de algarrobos, donde "los de arriba desde dicha punta han poseido y poseen los indios de Atacama, y los de abajo los indios de esta parcialidad sin permitir unos ni otros en sus cosechas que siempre las han dio á coger sin que se propasen de sus linderos" (Paz Soldán 1878: 55). Lo anterior permite sugerir que el valle de Quillagua era un territorio cuyos recursos eran objeto de superposición de derechos de uso. Ciertamente que los frutos del algarrobo eran apreciados y se les consideraban similares a los de San Pedro de Atacama y Canchones, aunque en apariencia destacaban por su dulzor y su condición de excelente forraje (García Gorroño 1934: 55).

Poca duda cabe que durante el período colonial este valle del curso inferior del río Loa era un espacio social dinámico construido por la multiplicidad de relaciones que allí convergían. Si se considera su vinculación directa con la costa el valor relativo es mayor, particularmente con Puerto Loa, desde donde se articulaba una red de interacciones con otros núcleos productivos costeros, como el área de Chomache-Guanillos.

Otro recurso existente en la costa y que ocupó un lugar particular fue el guano. Desde esa perspectiva, la desembocadura del Loa y Chomache-Guanillos formaría parte de una red de interacciones entre núcleos poblacionales productivos articulados por complementariedad ecológica y social, y cuyos espacios habitados más cercanos eran los valles de Guatacondo y Quillagua.

La relación de Chomache-Guanillos y el valle de Guatacondo se reconoce por el uso del guano en la agricultura del valle. Su cabecera era el pueblo de San Salvador de Guatacondo, pero se incluían los ayllus de Chipana, y Capuna u Ocapuna (Hidalgo 2004; Villalobos 1979). ${ }^{9}$ Al igual que los pagos del Chaiñar [sic], El Molino, La Palma, Tiquima, además de "un pago en el valle de Chilas [...], Tierras en Higua (Igua) y Capounisca". ${ }^{10}$ Espacios productivos que, a lo largo del período colonial se fueron organizando en torno al cultivo de alfalfa, hortalizas y frutales, junto con la continuidad de los sembradíos de maíz, papa y quinua (Riso Patrón 1924; Guerra 1975). Con poca duda, estos productos permitieron alimentar a quienes extraían los metales existentes en los yacimientos situados a lo largo de la quebrada, como los minerales de Challacollo, Chiclla, Collahuasi, cerro Ujina o Pereyra y Yabricoya que presentaban vetas de cobre, oro, plata y plomo (O'Brien 1765: documento transcrito por Hidalgo 2009; Riso Patrón 1924; Villalobos 1979; Bermúdez 1980). ${ }^{11}$ En estos se desarrollaron también actividades metalúrgicas centradas tanto en la fundición de los metales como en el proceso de fabricación de diversos artefactos. ${ }^{12}$

Para el siglo xIx, el área de Chomache-Guanillos es significada como un espacio de desembarcaderos, con pequeñas caletas entre Guanillos y Punta de Lobos: Agra, situada más al sur, y El Sombrero, hacia el norte. En ese mismo tramo existían "dos desembarcaderos muy conocidos por los pescadores de la provincia, y por los marinos del cabotaje, llamado el uno Chumachia y el otro La Cruz" (Billinghurst 1886: 71, cursiva del autor). Para comienzos del siglo xx, Riso Patrón refiere que Chomache, también conocido como Comache, "se abre en una comarca del todo desolada, abrigada del SSW por la punta del mismo nombre, a 7 kilómetros al SSE, de la punta Lobos" (Riso Patrón 1924: 209). El lugar era considerado abundante en depósitos de guano y minerales de cobre y plata que atraían a los cateadores (Espinoza 1897: 80 y 90).

Respecto de la relación con el valle y la quebrada cordillerana de Guatacondo hay evidencias, para fines del siglo XIX, de un antiguo camino tropero utilizado por "los vecinos de los caseríos de Quitala, Huatacondo, Tiquima, Tamentina, Maní, etc." en sus viajes hacia la costa (García Gorroño 1934: 52). Según el mismo autor, estos pobladores transitaban con animales cargados de frutas, verduras y alfalfa, que vendían en las covaderas de Guanillos al sur de Chomache y en la mina de oro La Paiquina, ubicada sobre la cordillera de la Costa al norte de la desembocadura del río Loa. En Guanillos, los pobladores de Guatacondo se aprovisionaban de pequeñas cantidades de guano destinadas a abonar sus tierras agrícolas, utilizando un sendero que atravesaba un área dotada de puquio llamado "Huatacondos" (Zolezzi 1993: 6). Al sur de Chomache, por la quebrada conocida como de los Guatacondos, asciende un camino rumbo al salar de Llamara hasta la zona bosque o Monte de La Soledad. Allí, a fines del siglo xIx, existía un pequeño asentamiento habitado solo por una familia que contaba con un pozo, rebaños de ovejas y cabras, y unas cuantas mulas y aves (Bowman 1942 [1924]: 51). Este pozo correspondería al "Puquio de Los Huatacondinos, en el Salar de Llamara, Monte de La Soledad, por los 


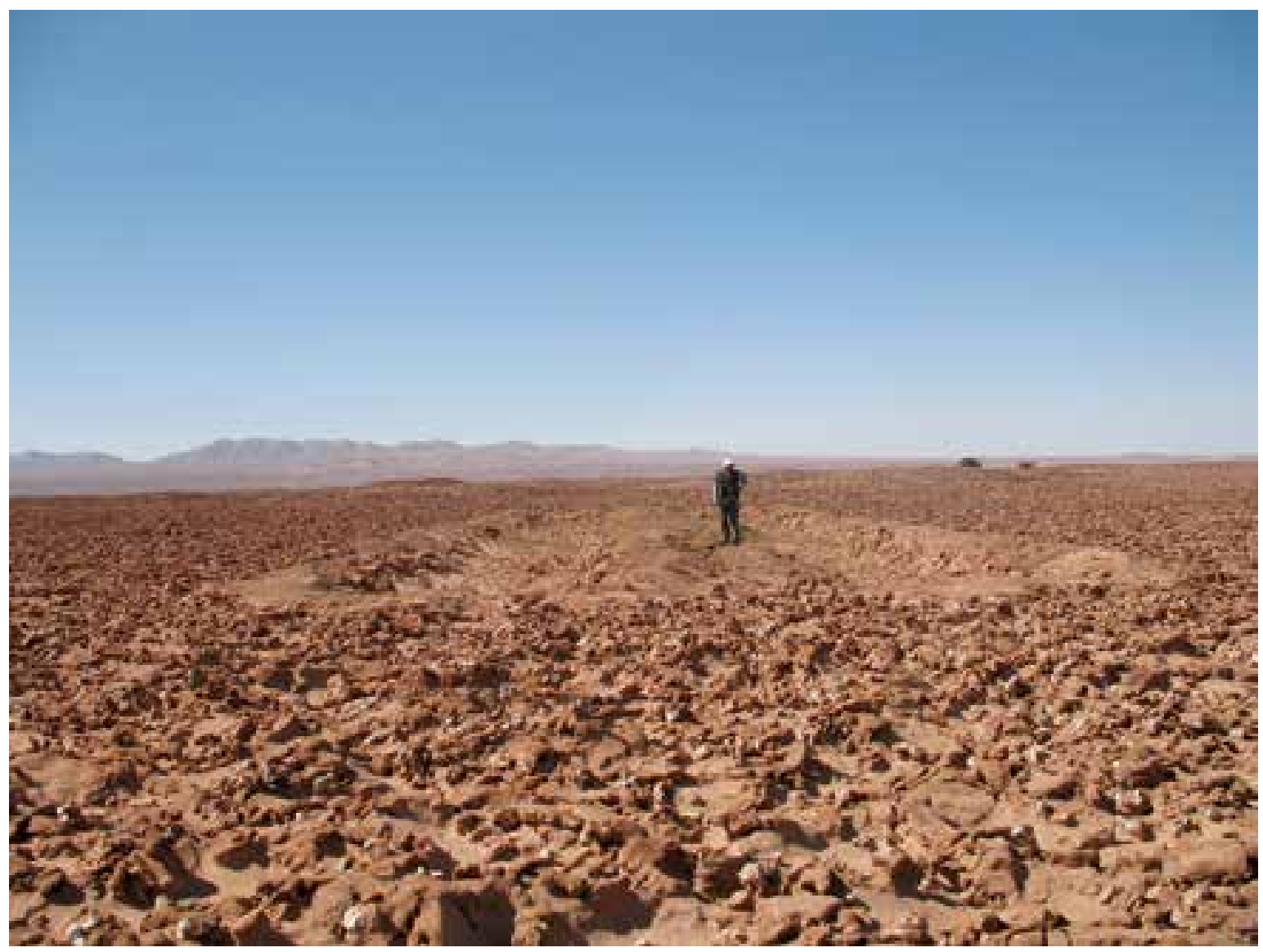

Figura 7. Canchones de cultivo en salar de Llamara.

Figure 7. Agricultural fields in the Llamara salt flat.

$21^{\circ} 12^{\prime}$ y $69^{\circ} 42^{\prime}$, que, aunque un poco salobre [...] se puede beber" (García Gorroño 1934: 51), donde además existían cultivos (Riso Patrón 1924: 717) (fig. 7).

Estos indicios sugieren que, en tiempos históricos o subactuales, el valle de Guatacondo mantenía su tradición productiva. Los puntos de cultivo más relevantes estaban emplazados en el fondo del valle, y en orden descendente, de oriente a poniente, se situaban en "Copaquire, Igua, Cautenicsa, Huatacondo, El Molino, Tiquima y Tamentica" (Billinghurst 1886: 56). El paraje de Copaquire contaba con "algunos alfalfares, siendo mui abundante en pastos de cordillera i arbustos, donde se crian algunos ganados de corderos i de llamas" (Riso Patrón 1924: 18). El caserío de Tiquima era considerado un área de cultivo "de pasto i hortalizas, tiene agua" (Riso Patrón 1924: 882). En las vertientes de Tamentica, en la desembocadura de la quebrada de Guatacondo, los viajeros se abastecían de agua, frutas y forraje para los animales (Bermúdez 1980; Riso Patrón 1924). A su vez, los recursos existentes en Tamentica se destinaban a abastecer las necesidades del mineral de Challacollo "que se halla solamente á 4 leguas de distancia" (Billinghurst 1886: 56-57).

Respecto del valle de Quillagua se sugiere que su relación con la costa se habría construido en torno a cultivos forrajeros, siendo central el uso de guano que permitía aumentar las cosechas de alfalfa y maíz (Riso Patrón 1924: 735). Para acceder al guano, arrieros del valle inferior del río Loa, "transitan entre el caserío de Quillagua y la costa, que, por lo general, son los vecinos del propio caserío, los cuales, con sus arrias de burros, van en busca de guano para fertilizar los terrenos en que se produce alfalfa, maíces, etc." (García Gorroño 1934: 53). Incluso arrieros o troperos de Quillagua, hasta por lo menos mediados de la década de 1960, se dirigían al área de la desembocadura del río Loa, y sus alrededores, para obtener recursos costeros, especialmente guano blanco y pescado. Este viaje se desarrollaba en seis días, contando con lugares de descanso y parada, como Calate situado a medio camino entre Quillagua y la desembocadura del Loa. ${ }^{13}$ La ruta también era utilizada, a comienzos del siglo xx, por pobladores de la denominada boca del 
Loa que viajaban a Quillagua para "cambiar pescados y almejas por té y trigo" (Rudolph 1928: 72).

A pesar de que la información documental del área de Chomache-Guanillos es breve, tanto para tiempos coloniales como subactuales, es posible sugerir una vinculación social y económica con los valles de Guatacondo y Quillagua, y el área de desembocadura del río Loa. Chomache-Guanillos habría cumplido una función económica semejante a Puerto Loa: generar excedentes productivos -guano, pescado seco y salado- orientados a las necesidades agrícolas y alimentarias de poblaciones tarapaqueñas del interior. Lo interesante es que Chomache aprovisionaba, preferencialmente, a las comunidades alojadas en el valle de Guatacondo. Puerto Loa en cambio aportaba a este último vía La Paiquina, aunque siguiendo el sendero del río Loa abastecía también a las comunidades en el oasis de Quillagua, cuyos algarrobos satisfacían las demandas de Pica-Guatacondo-Atacama. Esta función de consumo habría estado poderosamente dinamizada por el gran contingente humano necesario para las actividades metalúrgicas existentes en la costa y a lo largo de la quebrada de Guatacondo.

\section{El período prehispánico (900-1500)}

La evidencia arqueológica para la época posterior al 900 DC indica que, así como Chomache, otras localidades y rutas cercanas estaban en pleno funcionamiento al igual que en los períodos históricos siguientes. Sabemos que la red vial que articulaba las poblaciones del sistema colonial exhibe numerosos registros prehispánicos. Existen materiales que permiten concluir que su uso económico y social era significativo desde al menos el período anterior al Inka. Aunque las investigaciones arqueológicas han promovido la idea de un carácter formativo dominante para el valle de Guatacondo, sabemos que este fue un importante reducto de poblaciones del complejo Pica-Tarapacá (Tolosa 1963; Mostny 1970a y b). Si bien hasta ahora no existen estudios sistemáticos en el sector, evidencias como geoglifos, cementerios, hallazgos superficiales y fechados radiocarbónicos posteriores al Período Medio apoyan de manera convincente la importancia de esta zona como un núcleo residencial tarapaqueño, cuyo carácter económico y social pudo ser mayor a la idea de que sus funciones eran resultado de ser un simple enclave periférico o punto de tránsito obligado entre la costa y el altiplano (Mostny 1970a). ${ }^{14}$ Este sistema de asentamiento no era ajeno a los intereses de las gentes que residían en la localidad de Quillagua, pues aquí también se han registrado componentes tarapaqueños aunque en asociación a ocupaciones atacameñas, coexistencia que los arqueólogos han interpretado desde muy temprano como una bisagra o frontera intercultural entre diferentes poblaciones agropastoriles (Latcham 1933; Agüero 1997; Agüero et al. 1997 y 1999).

Los registros históricos son categóricos respecto de las riquezas mineras asociadas a la quebrada de Guatacondo. La magnitud prehistórica de las actividades asociadas es por ahora desconocida, pero la información primaria indica que fueron desarrolladas desde el Formativo hasta el Período Inka en las nacientes de este río, en el valle y las cercanías del actual mineral de Collahuasi (Lynch \& Núñez 1994; Graffam et al. 1995-1996). Si aceptamos la hipótesis de que la minería prehispánica fue uno de los recursos que alentaron el poblamiento y el control de la quebrada, entonces podemos sugerir que esto debió demandar importantes aprovisionamientos logísticos (p. e., alimentos, leña, forraje), racionamiento lógico elemental dado que las condiciones técnicas del trabajo minero requieren del gasto de importantes fuerzas de trabajo en actividades al margen de la subsistencia.

Aunque la arqueología del valle es deficitaria en la cobertura general del total de sus períodos históricos y culturales, la existencia de extensos campos de cultivos y gigantescas obras de irrigación a lo largo de al menos $30 \mathrm{~km}$ de la quebrada, entre el oasis de Tiquima y la estación de ferrocarril de Ramaditas, hacen difícil atribuir esta agencia a poblaciones formativas de manera exclusiva (De Bruyne 1963), menos aún si consideramos la continuidad ocupacional y productiva del área hasta épocas coloniales. Nuestras observaciones de campo juegan a favor de este enunciado, pues estas sugieren que existe una estrecha homología espacial entre esta extensa superficie agrícola y la presencia de geoglifos con iconografía del PIT, número que supera ampliamente a los registros informados por la literatura científica (p. e., Clarkson \& Briones 2001). Con poca duda, investigaciones futuras permitirán dimensionar correctamente la posición de esta localidad arqueológica en el contexto regional. Por ahora aceptaremos la conclusión de Grete Mostny de que el área tuvo la "presencia de una vida sedentaria de agricultores desde principios de nuestra era hasta los tiempos incásicos" (1970a: 285-286).

Aunque no conocemos con exactitud la variedad de cultivos prehispánicos en Guatacondo, es admisible suponer, por los hallazgos en localidades vecinas, que implementaron una agricultura del maíz, la quinua y el algodón, recursos que fueron probablemente complementados por la producción zonal como las del oasis de Quillagua y la costa entre la desembocadura del río Loa y Punta de Lobos. En los años treinta del siglo pasado, Ricardo Latcham (1933) excavó en el oasis algunos cementerios de esa época, recuperando ollas y cestos con 
harinas de algarrobo y quinua, y también con mazorcas, harina y maíz reventado (pululo). No faltaban aquí los productos marinos, como el pescado seco. Si consideramos que esta localidad y Tamentica están unidas por un único trazado de senderos, jalonados por campos de grandes figuras ejecutadas sobre las planicies y lomajes, es relativamente claro que este pudo permitir la circulación de dichos productos en un ambiente de intercambio y/o redistribución (p. e., Clarkson 1999).

De la desembocadura del río Loa, donde hay extensos cementerios con materiales tarapaqueños y atacameños, Quillagua pudo obtener preferencialmente productos marinos y fertilizantes naturales (Spahni 1967; Núñez 1971). El camino que corre junto al río desde la costa hasta el valle es prueba de ello, pues los registros muestran un uso continuo desde el Arcaico Medio en adelante (Pimentel 2009). Sin embargo, es posible que las poblaciones de Guatacondo hayan tenido también un acceso privilegiado a estos mismos recursos, puesto que desde la zona de La Paiquina, en las cumbres al norte de la desembocadura, existe una huella que se interna directamente hacia el salar de Llamara y Monte de La
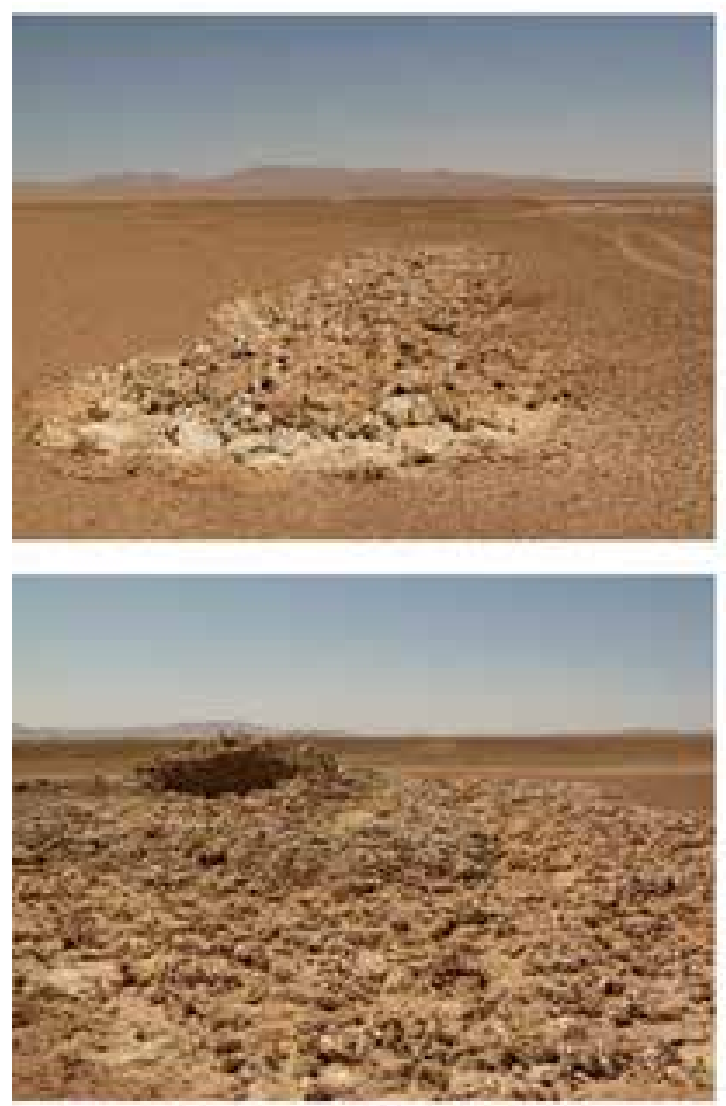

Figura 8. Posta prehispánica e histórica en salar de Llamara.

Figure 8. Waystation on the Llamara salt flat used in pre-Hispanic and early Hispanic times.
Soledad. Este lugar empalma con la ruta que proviene desde Chomache-Guanillos, donde hemos reconocido una posta y otras instalaciones que forman parte de un pequeño sistema de asentamiento con cerámica Charcollo asociado a los puquios del salar de Llamara (fig. 8). Aunque el primer sitio no mostró materiales tardíos, la presencia de collcas y un tambo inkaico en las cercanías de La Paiquina, en asociación a registros inka imperial a lo largo del valle de Guatacondo, sugieren que estos flujos pudieron ser aprovechados por la administración provincial cusqueña. ${ }^{15}$

\section{CHOMACHE 58 Y EL CONTEXTO VISUAL REGIONAL}

Dada la posición del área de Chomache-Guanillos -con reservas de pesca y guano para la agricultura- y la evidencia arqueológica relacionada, su vinculación con la quebrada de Guatacondo resulta una sugerencia aceptable. Los vínculos de articulación económica no solo aparecen respaldados por la presencia de productos
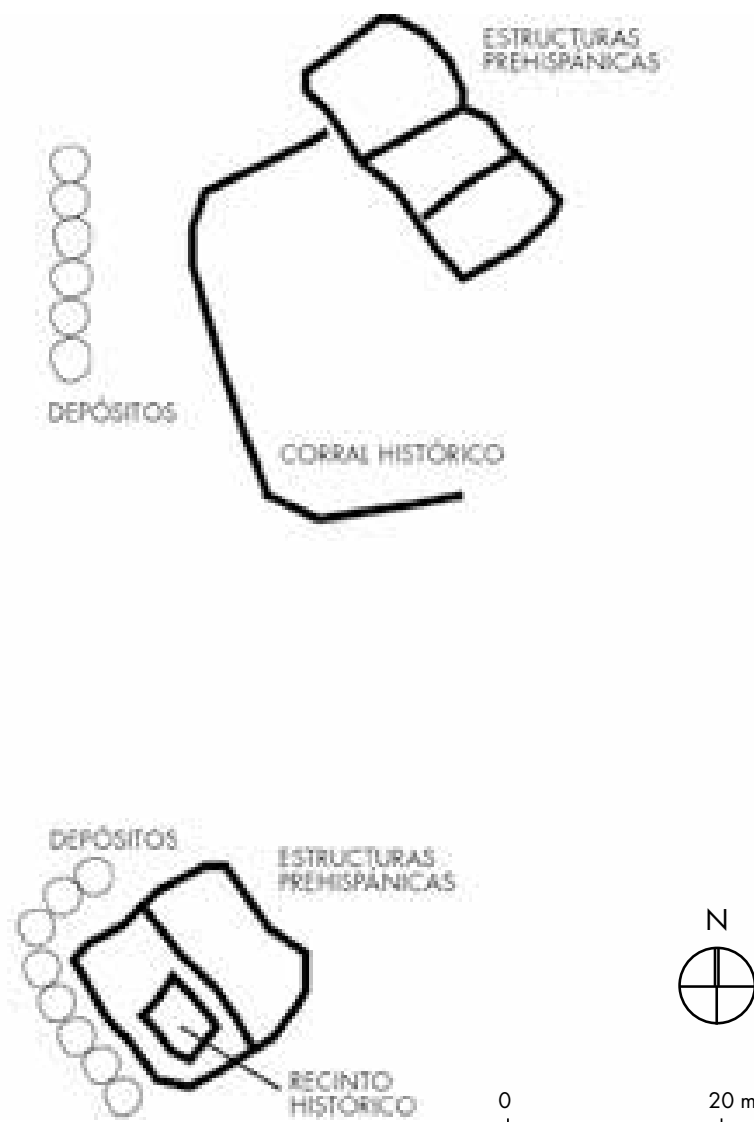
agrícolas y metalurgia en el sitio habitacional costero, sino especialmente por la iconografía de Chomache 58.

Este patrimonio visual costero expresa un inusual consentimiento con las producciones artísticas de las poblaciones del interior, pero que dado su emplazamiento y técnica sugiere un componente local relativo a los cazadores recolectores marinos que coparticipaban de un ideal de integración económica, social y cultural promovido por los agricultores y los pastores tarapaqueños. Estas formas visuales de referencia costera son recurrentes en el repertorio gráfico de los geoglifos del desierto interior, con representaciones de grandes peces o mamíferos marinos y balsas tripuladas que aparecen también en grabados de la región (p. e., Mostny \& Niemeyer 1983; Briones \& Castellón 2005). Este dispositivo iconográfico permitía la construcción de un sentido de pertenencia que integraba diversas ecozonas a las que se les atribuye un valor de referencia simbólica.

La amplia distribución espacial de las imágenes de Chomache 58 y la diversidad de técnicas y soportes -como arte rupestre, cestería, tejidos o cerámica- contribuyeron a producir un efecto de redundancia necesario para la construcción de un imaginario común entre agropastores y cazadores recolectores marinos de Tarapacá. Se trata de un proceso germinal de un tipo de multiculturalismo cuya eficacia iba más allá de la circulación de bienes, pues proporcionaba un capital de información que aportaba a una cohesión y solidaridad social superior a las prácticas de intercambio.

\section{CONCLUSIONES}

Los estudiosos de los Andes han elevado la complementariedad ecológica a la categoría de un ideal andino, como si esto fuera algo peculiar a todas las comunidades cuyos territorios se extienden al amparo de la cordillera de los Andes. Esto es aceptable solo porque sabemos que ninguna sociedad vive en el total aislamiento y en la absoluta autosuficiencia económica. Lo cierto es que siempre habrá fórmulas y niveles de integración e interacción social para canalizar el flujo diferencial de información, bienes y personas. Son modos cuya combinatoria será necesariamente particular según las comunidades involucradas en la red, y vínculos que requerirán de un adecuado sistema de creencias que proporcione contenidos y límites para la definición de su propio "ideal". La extrema redundancia del sistema visual al que pertenece el panel rupestre Chomache 58 y su amplia pero acotada extensión geográfica, nos hace suponer la presencia de una comunidad de actores sociales cuyos lazos les permitían un tipo de solidaridad social centrífuga en el orden de lo simbólico o cultural. Probablemente, estas formas de interacción tarapaqueña no solo permitieron complementariedad ecológica, sino, al mismo tiempo, una complementariedad social, tal vez mediante parentesco y "doble domicilio", como ocurre hasta hoy con los habitantes de Quillagua y Guatacondo.

RECONOCIMIENTOS A Mauricio Uribe y su equipo por hacer esto posible. Particularmente a Carolina Agüero, Estefanía Vidal, Constanza Pellegrino, Rolando Ajata y Elizabeth Shaeffer, por su colaboración en el registro de este y otros sitios de arte rupestre tarapaqueño. A Magdalena García, Josefina González, Jimena Valenzuela y Pablo Méndez-Quirós por su aporte a este artículo. A Paulina Chávez por sus dibujos. Y a Gerardo Mora por su atenta lectura. Este artículo es resultado del proyecto FONDECYT 1080458.

\section{NOTAS}

1 Coordenadas WGS84 Huso 19 UTM: 382703E 7663640N.

2 Como 'geométrico compuesto' designamos a representaciones que involucran una figura geométrica con apéndices o bien dos o más elementos geométricos que se replican simétricamente.

3 Utilizaremos "tarapaqueño(a)" para significar una tradición cultural que se origina en la Región de Tarapacá durante el Período Formativo y que perdura hasta tiempos históricos, pero cuya influencia trasciende sus límites geográficos. De forma similar se aplica "atacameño(a)", atendiendo a la tradición cultural propia del salar de Atacama.

${ }^{4}$ Se entiende traslación como la repetición sucesiva de un diseño sobre un eje lineal, al menos un paso hacia la derecha o izquierda, en igual distancia (Washburn \& Crowe 1988).

5 Excepción la constituye un caso en que las piernas fueron dibujadas de forma oblicua divergente, sugiriendo la acción de correr o saltar, y que además presenta un elemento extrasomático de forma indeterminada.

${ }^{6}$ Respectivamente Beta-256618 (material carbonizado) y Beta256619 (material vegetal), 2 sigmas calibración.

7 Operativamente separamos local de foráneo. Mientras este incluye pampa, oasis y valles interiores; aquel, la franja costera con intermareal, aguadas y "oasis de niebla", "formación de lomas" o "praderas del desierto" que, ubicados en la cordillera de la Costa (600-1000 msnm), desarrollan vegetación gracias a la camanchaca o neblina que se introduce desde el océano Pacífico.

8 Todo esto produjo cambios en la organización del trabajo indígena, siendo la más clara la utilización de mano de obra indígena para las actividades económicas de extracción, producción y transporte de insumos (Odone 1994).

9 Situado en la parte superior de la quebrada de Maní (Bermúdez 1980: 172).

${ }_{10}$ Testamento de Margarita de Soza en Legajo de contratos diversos Tarapacá y Huantajaya AJI, legajo 327, pieza 8 f. 25, citado por Villalobos 1979: 79

${ }^{11}$ La información colonial permite detectar, en el cerro de Ujina o Pereyra, la presencia de poblaciones procedentes de Atacama y Lípez que abastecían al mineral "con Carnes frescas y secas, Arinas, Maíz y otros Comestibles en abundancia, cuio abasto es de mayor importancia, pues esta Provincia no es capáz de mantener por si sola dicho Mineral" (O'Brien 1765, f. 52v transcrito por Hidalgo 2009: 38). Siglos más tarde llegaban hasta allí habitantes de Guatacondo con mercancías que eran transportadas en mulas.

12 Hacia 1765 existían en el mineral cerro de Ujina o Pereyra, y en sus inmediaciones, en Viquintipa y Miño, labores de fundición asociadas a la fabricación "de fondos, Granalla, Campanas, Almadanetas, Lampas, Combas, y otros menesteres", que eran enviados a Potosí (O'Brien 1765: fs. 51r-v transcrito por Hidalgo 2009: 37). 
13 Información recogida por Carolina Odone en Quillagua, los años 1988, 1991 y 1995.

14 Desde las primeras investigaciones arqueológicas en la aldea formativa de Guatacondo (Mostny 1970) se posee una fecha radiocarbónica obtenida sobre un fogón arriba de un techo temprano colapsado, datación que corresponde a $775 \pm 160$ AP y cuya calibración al 99\% la sitúa entre el 950 y 1446 después de Cristo.

15 Ver Núñez 1987.

\section{REFERENCIAS}

ADÁN, L. \& S. URBINA, 2004. Historia arquitectónica de la localidad de Pisagua (I Región, Chile): una tradición olvidada en los períodos tardíos del área Pica-Tarapacá [online] http://www. memoriachilena.cl/temas/documento_detalle.asp?id=MC0038246 [Citado 02-09-11].

Agüero, C., 1997. Una versión sobre el encuentro de Atacama y Tarapacá a través de los textiles de los cementerios de Quillagua. Boletín de la Sociedad Chilena de Arqueología 23: 20-22, Santiago.

— 2007. El vestuario en la conformación y consolidación de la identidad cultural de las poblaciones de Tarapacá durante el Período Intermedio Tardío. Tesis para optar al Grado de Magíster en Antropología con mención en Arqueología, Universidad Católica del Norte-Universidad de Tarapacá.

Agüero, C.; M. Uribe, P. Ayala \& B. Cases, 1997. Variabilidad textil en el valle de Quillagua durante el Período Intermedio Tardío: Una aproximación a la etnicidad. Estudios Atacameños 17: 263-290.

— 1999. Una aproximación arqueológica a la etnicidad y el rol de los textiles en la construcción de la identidad cultural en los cementerios de Quillagua. Gaceta Arqueológica Andina 25: 167-198, Lima.

Ballester, B. \& F. Gallardo, 2011. Prehistoric and Historic networks on the Atacama Desert coast (northern Chile). Antiquity 85 (329): 875-889. Oxford: Oxford University Press.

Bermúdez, O., 1980. La población indígena de la Doctrina de Pica. Segunda mitad del siglo xvIII. Chungara 6: 145-215.

Billinghurst, G., 1886. Estudio sobre la geografía de Tarapacá. Santiago: Imprenta de El Progreso.

— 1893. La irrigación en Tarapacá. Santiago: Imprenta y Librería Ercilla.

Bowman, I., 1942 [1924]. Los senderos del desierto de Atacama. Santiago: Imprenta Universitaria.

Briones, L. \& C. Castellón, 2005. Catastro de geoglifos. Provincia de Tocopilla, Región de Antofagasta. Antofagasta: Consejo Nacional de la Cultura y las Artes, FonDART.

Briones, L. \& J. Chacama, 1987. Arte rupestre de Ariquilda: Análisis descriptivo de un sitio con geoglifos y su vinculación con la prehistoria regional. Chungara 18: 15-66.

Briones, L.; L. NúÑEz \& V. STANDEn, 2005. Geoglifos y tráfico prehispánico de caravanas de llamas en el desierto de Atacama (norte de Chile). Chungara 37 (2): 195-223.

Cerda, P.; S. Fernández \& J. Estay, 1985. Prospección de geoglifos de la provincia de Iquique, I Región Tarapacá, norte de Chile: Informe preliminar. En Estudios de Arte Rupestre, C. Aldunate, J. Berenguer \& V. Castro, Eds., pp. 331-348. Santiago: Museo Chileno de Arte Precolombino.

Clarkson, P., 1999. Considérations historiques et contextualisation de la recherche sur les géoglyphes au Chili. Anthropologie et Sociétés 23 (1): 125-150, Québec.

Clarkson, P. \& L. Briones, 2001. Geoglifos, senderos y etnoarqueología de caravanas en el desierto chileno. Boletín del Museo Chileno de Arte Precolombino 8: 35-45.

Dauelsberg, R., 1984. Taltape: Definición de un tipo cerámico. Chungara 12: 19-39.

De BRuYNe, E., 1963. Informe sobre el descubrimiento de una área arqueológica. Museo Nacional de Historia Natural, Publicaciones Ocasionales 2: 1-16, Santiago.
EspinosA, G., 1998. Lari y Jamp'atu. Ritual de la lluvia y simbolismo andino en una escena de arte rupestre de Ariquilda 1, norte de Chile. Chungara 28 (1 y 2): 133-157.

EsPINOZA, E., 1897. Jeografia descriptiva de la República de Chile. Santiago: Editorial Barcelona.

Gallardo, F., 2009a. Sobre la composición y la disposición en el arte rupestre de Chile: consideraciones metodológicas e interpretativas. Magallania 37: 85-98, Punta Arenas.

- 2009b. Social interaction and early rock art styles in the Atacama Desert (northern Chile). Antiquity 83: 619-633. Oxford: Oxford University Press.

García, C., 2009 Ms. Tipología lítica en dos sitios arqueológicos de la provincia de Iquique. Informe parcial arqueológico, Proyecto FONDECYT N ${ }^{\circ} 1080458$.

García Gorroño, B., 1934. Descripción geográfica de la provincia de Tarapacá. Revista Chilena de Historia y Geografía LXXVI (83): 32-96, Santiago.

González, M. J., 2009 Ms. Arqueofauna de sitios costeros de la I Región, Período Formativo. Informe parcial arqueológico, Proyecto FONDECYT N ${ }^{\circ} 1080458$.

Graffam, G.; A. Carevic \& M. Rivera, 1995-1996. Evidencias metalúrgicas de fundición de cobre en el sitio Formativo Tardío de Ramaditas, quebrada de Guatacondo, Provincia de Iquique, Chile. Estudios Atacameños 12: 53-67.

GuerRA, P., 1975. Guatacondo: Un caso de transformación agraria y cultural en la zona árida. Revista Norte Grande I (3-4): 387400, Santiago.

Hidalgo, J., 2004. Historia andina en Chile. Santiago: Editorial Universitaria.

— 2009. Civilización y fomento: La "Descripción de Tarapacá" de Antonio O'Brien, 1765. Versión paleográfica de Jorge Hidalgo. Chungara 41 (1): 5-44.

HornKOHL, H., 1954. Los petroglifos de Gatico en la Provincia de Antofagasta, Chile. Revista Chilena de Historia Natural 12: 152-154, Santiago.

Latcham, R., 1933. Notas preliminares de un viaje arqueológico a la localidad de Quillagua. Revista Chilena de Historia y Geografia XXXVII: 130-138, Santiago.

Llagostera, A., 1989. Caza y pesca marítima (9000-1000 AC). En Culturas de Chile. Prehistoria. Desde sus origenes hasta los albores de la conquista, J. Hidalgo, V. Schiappacasse, H. Niemeyer, C. Aldunate \& I. Solimano, Eds., pp. 57-80. Santiago: Editorial Andrés Bello.

LYNCH, T. \& L. NÚÑEZ, 1994. Nuevas evidencias inkas entre Kollahuasi y Rio Frio (I y II regiones de Chile). Estudios Atacameños 11: $145-164$.

Martínez, J. L., 1985. Información sobre el comercio de pescado entre Cobija y Potosí, hecha por el Corregidor de Atacama, Don Juan Segura (19 de Julio de 1591). Cuadernos de Historia 5: 161-171, Santiago.

Meighan, C. W., 1980. Archaeology of Guatacondo. En Prehistoric trails of Atacama: Archaeology of northern Chile (Monumenta Archaeologica 7), C. W. Meighan \& A. L. True, Eds., pp. 99-126. Los Angeles, CA: Institute of Archaeology, University of California.

MÉNDEZ-Quirós, P., 2009 Ms. Estratigrafía y sistema de asentamientos de la costa arreica durante el Período Formativo. Una reflexión preliminar. Informe parcial arqueológico, Proyecto FONDECYT $\mathrm{N}^{\circ} 1080458$

Montell, G., 1926. An Archaeologycal Collection from the Río Loa Valley, Atacama. Oslo Etnografiske Museums Skrifter bind 5 hefte 1 , Oslo.

Mostny, G., 1970a. Arqueología de la Quebrada de Guatacondo. Órbita Revista de Ciencia y Tecnología 6: 6-20, Santiago.

— 1970b. La subárea arqueológica de Guatacondo. Boletín del Museo de Historia Natural XXIX: 271-287, Santiago.

Mostny, G. \& H. Niemeyer, 1983. Arte rupestre chileno. Santiago: Ministerio de Educación, Departamento de Extensión Cultural.

MurRa, J., 1972. El control vertical de un máximo de pisos ecológicos en la economía de las sociedades andinas. En Visita de la Provincia de León de Huánuco en 1562, Volumen 2, 
J. Murra, Ed., pp. 427-476. Huánuco: Universidad Nacional Hermilio Valdizán.

Niemeyer, H. \& V. Schiappacasse, 1981. Aportes al conocimiento del Período Tardío en el extremo norte de Chile. Análisis del sector de Huancarane del valle de Camarones. Chungara 7: 3-103.

NúÑEZ, L., 1962. Contactos culturales prehispánicos entre la costa y la subcordillera andina. Boletín de la Universidad de Chile 31: 42-47, Santiago.

- 1971. Secuencia y cambio en los asentamientos humanos de la desembocadura del río Loa en el norte de Chile. Boletín de la Universidad de Chile 112: 3-25, Santiago.

- 1976. Geoglifos y tráfico de caravanas en el desierto chileno. En Homenaje al Dr. Gustavo Le Paige, S. J., H. Niemeyer, Ed., pp. 147-201. Antofagasta: Universidad del Norte.

1985. Petroglifos y tráfico en el desierto chileno. En Estudios de Arte Rupestre, C. Aldunate, J. Berenguer \& V. Castro, Eds., pp. 243-264. Santiago: Museo Chileno de Arte Precolombino.

1987. Tráfico de metales en el área surandina. Cuadernos del Instituto Nacional de Antropología 12: 87-120, Buenos Aires.

NúÑeZ, L. \& L. Briones, 1968. Petroglifos del sitio Tarapacá-47 (Provincia de Tarapacá). Estudios Arqueológicos 3-4: 43-75, Antofagasta.

NúÑEZ, L. \& T. Dillehay, 1995 [1979]. Movilidad giratoria, armonía social y desarrollo en los Andes Meridionales: patrones de tráfico e interacción económica (Ensayo). Antofagasta: Universidad del Norte.

NúÑEz, P., 2002. Chacance los primeros pampinos. Museo Comuna de María Helena. Fondo de Identidad y Cultura de la II Región. Antofagasta: Gobierno Regional.

NúÑEz, P. \& R. ConTRERAs, 2006. El arte rupestre de Taltal, norte de Chile. En Actas del V Congreso Chileno de Antropología, pp. 348-357. San Felipe: Colegio de Antropólogos de Chile.

Odone, C., 1994. La territorialidad indígena y española en Tarapacá colonial (siglos XVI-XVIII): Una proposición. Tesis para optar al grado de Licenciada en Historia. Instituto de Historia, Pontificia Universidad Católica de Chile.

2011 Ms. La quebrada de Tarapacá: Los espacios y sus relaciones (siglos XVI-Xx). Informe etnohistórico, Proyecto VID SOC08/16-2, Universidad de Chile.

OYARZún, A., 1979. Estudios antropológicos y arqueológicos. Santiago: Editorial Universitaria.

Paz SoldÁn, M. F., 1878. Verdaderos límites entre el Perú y Bolivia. Lima: Imprenta Liberal.

Pimentel, G., 2009. Las huacas del tráfico. Arquitectura ceremonial en rutas prehispánicas del desierto de Atacama. Boletín del Museo Chileno de Arte Precolombino 14 (2): 9-38.
Riso Patrón, L., 1924. Diccionario geográfico de Chile. Santiago: Imprenta Universitaria.

Riveros, R., 2009 Ms. Gotas y anzuelos: Evidencias de actividades metalúrgicas durante el Período Formativo en el litoral de Iquique, Región de Tarapacá, Chile. Informe parcial arqueológico, Proyecto FONDECYT No 1080458.

Rudolph, W., 1928. El Loa. Revista Chilena de Historia y Geografía 59 (63): 66-89, Santiago.

RYDEn, S., 1944. Contributions to the Archaeology of the Rio Loa Region. Göteborg: Elanders Boktryckeri Aktiebolag.

SpaHNI, J.-C., 1967. Recherches archéologiques à l'embouchure du río Loa (côte du Pacifique-Chili. Journal de la Société des Américanistes 61: 179-239, Paris.

Tolosa, B., 1963. Petroglifos de Tamentica. Museo Nacional de Historia Natural Noticiario Mensual 86: 1.

Urbina, S.; L. Adán, C. Moragas, S. Olmos \& R. Ajata, 2009 Ms. Arquitectura y asentamientos formativos en la costa desértica de Tarapacá, norte de Chile. Informe parcial arqueológico, Proyecto FONDECYT N 1080458.

URIBE, M., 1999. La cerámica de Arica 40 años después de Dauelsberg. Chungara 31 (2): 189-228.

— 2004. Alfarería, arqueología y metodología. Aportes y proyecciones de los estudios cerámicos del Norte Grande de Chile. Tesis para obtener el grado de Magíster en Arqueología. Facultad de Ciencias Sociales, Universidad de Chile.

— 2009. El Período Formativo de Tarapacá y su cerámica: Avances sobre complejidad social en la costa del norte grande de Chile (900 AC-800 DC). Estudios Atacameños 37: 5-27.

Valenzuela, J., 2009 Ms. El material malacológico de sitios costeros de Tarapacá. Informe parcial arqueológico, Proyecto FONDECYT $\mathrm{N}^{\circ} 1080458$

VIDAL, A. \& M. GarCía, 2009 Ms. Uso del espacio e interacción con la flora de la costa de Tarapacá. Análisis del material vegetal de asentamientos vinculados al Período Formativo. Informe parcial arqueológico, Proyecto FONDECYT N ${ }^{\circ} 1080458$.

VilcheS, F. \& G. CABELLO, 2011. Variaciones sobre un mismo tema: El arte rupestre asociado al complejo Pica-Tarapacá, norte de Chile. Chungara 43 (1): 37-52.

Villalobos, S., 1979. La economía de un desierto. Tarapacá durante la Colonia. Santiago: Ediciones Nueva Universidad.

WaSHBURN D. \& D. Crowe, 1988. Theory and practice of plane pattern analysis. Washington, D. C.: University of Washington Press.

Zlatar, V., 1984. Cementerio prehispánico Pica-8. Antofagasta: Universidad de Antofagasta.

Zolezzi, M., 1993. Pampa del Tamarugal. La destrucción del Monte de La Soledad (ciclo salitrero). Revista Camanchaca 14: 6-8, Iquique. 